\title{
Re-encuadrar dentro del encuadre: miradas a un encuentro cine-educación*
}

\section{//Refocusing a focus Other perceptions \\ triggered by movies and education \\ convergence}

\begin{tabular}{l|l} 
Investigaciones & $\begin{array}{l}\text { de Educación, N. } 63 . \\
\text { Segundo semestre de 2012, }\end{array}$
\end{tabular}

Bogotá, Colombia.

\section{//Re-enquadrar dentro do enquadre: os outros olhares que impulsionam o encontro cinema-educação}

\section{Dulfay Astrid González Jiménez**}

\begin{abstract}
Artículo movilizado por el proyecto de investigación "Examinados, aprobados y evaluados: arqueología de las prácticas evaluativas en Colombia, asesorado por el Dr. Alberto Martinez Boom en el marco de la formación doctoral en Educación en la Universidad Pedagógica Nacional.

Estudiante de segundo año del Doctorado Interinstitucional en Educación de la Universidad Pedagógica Nacional. Docente-investigadora de la Facultad de Psicología de la Universidad de San Buenaventura de Cali, fundadora y coordinadora del Grupo de Investigación en Evaluación y Calidad de la Educación GIECE. Psicóloga y Filósofa de formación con estudios de Maestría en Filosofía de la Universidad del Valle. Correo electrónico: dulfayastrid@gmail.com
\end{abstract}

\section{Resumen}

Este artículo presenta algunas de las reflexiones suscitadas en un seminario de formación doctoral, en el que a partir de la relación pedagogía-educación-cine, y a propósito del análisis de algunas películas, se introdujo la plataforma investigativa para repensar e interrogar algunos temas de partida de los proyectos de doctorado. El artículo se divide en tres partes, una presentación del contexto de reflexión; algunas apuntes sobre las incitaciones, a propósito de la relación cine-educación; y algunas inquietudes desde dos películas desde las cuales se leyeron críticamente asuntos claves para pensar hoy, de otras formas, la investigación en educación.

El cine favorece lecturas agudas de la forma educación, y la educación, a través del cine, incita a re-encuadrar la propia mirada, a sospechar sobre lo naturalizado en educación, y a capturar y a detenerse sobre aspectos incluso olvidados e ignorados en investigación educativa.

\section{Abstract}

The article presents some of the reflections and bets carried out in a seminar of doctoral formation in which so pretext of the relation pedagogy- education-cine, and about the analysis of some movies, favored the platform investigation to rethink and to interrogate some topics of item of the projects of Ph.D. The article divides in three parts, a presentation of the context of reflection; some stitches it brings education cinema over of the incitements about the relation; and the analysis of two movies with common denominators and from which there were read critically matters key to think today of other forms the investigation about education.

Today the cinema favors sharp readings of the form education and the education across the cinema incites to look of other manners at the own look that is formed, among other things, across the education.

\section{Resumo}

O artigo apresenta algumas das reflexões e apostas levadas a cabo em um seminário de formação doutoral em que, sob o pretexto da relação pedagogia-educação-cinema, e a propósito da análise de alguns filmes, se favoreceu a plataforma investigativa para repensar e questionar alguns temas de partida dos projetos de doutorado. $\mathrm{O}$ artigo está dividido em três partes: uma apresentação do contexto de reflexão; alguns apontamentos sobre as provocações a propósito da relação educação-cinema; e a análise de dois filmes com denominadores comuns, desde os quais foram lidos criticamente assuntos-chave para pensar de outras formas, hoje, a investigação em educação. Atualmente, o cinema favorece leituras agudas da forma educação e a educação através do cinema incita a olhar de outros modos o próprio olhar que se configura, entre outras coisas, através da educação.

\section{Palabras Clave}

Educación, mirada a través del cine, forma escolar, encuadre, modos de ver.

\section{Keywords}

Education, view throughout the cinema, dilution of the teacher, setting, school.

\section{Palavras chave}

Educação, olhar através do cinema, diluição do professor, enquadre, escola. 


\section{¿Re-encuadrar para qué tipo de encuadre?}

La elección de la metáfora del cine reencuadre-encuadre para el título de este escrito no es un antojo, mucho menos arbitrio; recoge una búsqueda para otras formas de pensar, una búsqueda en torno al límite y un acercamiento temeroso a la dislocación en el investigar.

El encuadre en el cine cumple un papel fundamental. Una película es posible entre otras cosas por los miles de fotogramas dispuestos de manera secuencial (cada segundo pasan 24 fotogramas por la pantalla, los cuales son organizados en una unidad, en planos). Estos, intencionalmente organizados en planos, constituyen organizaciones de realidad, son encuadres de la realidad que revelan el objetivo e intencionalidad de quien hace la captura y el ordenamiento.

Todo encuadre a la vez que captura, visibiliza, manipula, organiza, también prescinde, limita y suprime. El encuadre hace ver, porque incluye, estructura, da un orden, pero también excluye, deja por fuera aquello que no se incluye como parte de la unidad. El encuadre en el cine es un ordenamiento, y la sumatoria y relación de los encuadres, permite ordenamientos diversos, composiciones, hasta dar forma a una realidad: la realidad cinematográfica.

El encuadre no se agota, ni se reduce a un límite físico que separa la ficción de la realidad. Al establecer los límites de la imagen se está tomando la decisión sobre qué incluir y qué dejar fuera, igualmente sobre las formas o mecanismos para incluirlo y cómo incluirlo. Lo que se deja fuera suele ser presentado como poco relevante, de escaso interés, se vuelve una especie de desecho. Lo que se incluye también define el espacio visual, y ordena y organiza los elementos dentro del cuadro.

En investigación, el investigador hace encuadres, incluye, pero también deja por fuera, también invisibiliza, deja desechos. Una de las tareas fundamentales con respecto a los puntos de partida en la formación doctoral y a propósito del cine, era indagar, sospechar, detenerse sobre los encuadres desde los cuales se construyen realidades investigativas en educación. Los desechos, los vestigios, lo incluido-excluido desempeña un papel fundamental.

¿Qué encuadres prefijados tenemos de la educación, que sería posible interrogarlos, desnaturalizarlos y descreerlos a través del cine? ¿Qué re-encuadres nos propone hoy el cine con respecto a 
la educación para que sean posibles otras formas de mirarla sospechando de las verdades que enuncian su supuesta naturaleza? ¿Sobre qué encuadres reposan los veredictos de la educación, que parten incluso de la investigación, y que requieren hoy ser interrogados y mirados desde el afuera, desde los bordes? ¿Cómo hacer del cine que mira a la educación y de la educación que mira el cine una estrategia para ubicarse entre el adentro y el afuera del encuadre, para el pensamiento de los bordes? ¿Qué encuadres y composiciones hace el cine de la educación para mirar, visibilizar, organizar, ordenar aquello que con extrañeza como espectadores redescubrimos?

El cine encuadra, incluye lo excluido, crea realidades desde las cuales se interroga la realidad del espectador. El cine reubica en planos haciendo visible de otros modos lo que se aplana en lo social. El cine ofrece redimensionamientos de la educación que ponen en jaque los arbitrios y omnipresencias de los discursos escolares, y a su vez, la educación hace usos diversos del cine, que van desde tecnologías visuales para la atención, hasta pedagogías de la imagen que permiten interrogar las realidades aparentemente no transformables sobre la educación misma.

[...] El cine es hoy un lugar de experimentación que permite el juego, la composición, la variación de planos, la comprensión de la disconti- nuidad, la variación del tiempo y del espacio, estos y otros elementos son articulables a las problemáticas académicas propias de la investigación, además moviliza de manera decisiva al establecimiento de nexos de un estudiante de educación avanzada con la cultura y con el pensamiento. (Martínez, 2011, p. 1)

Desde el cine que mira a la educación, desde la mirada que crea el cine sobre la educación y desde la mirada que mira a quien mira el cine en educación, era posible el reencuadre para otras formas de pensar y para otros modos de ver.

De aquí la apuesta de re-encuadrar dentro del encuadre como posibilidad de pensamiento desde los bordes, del afuera para la investigación y, de aquí la elección de dos películas producidas y dirigidas por cineastas iraníes, Abbas Kiarostami y Samira Makhmalbaf, quienes apuestan por otros planos, campos de visión y otros encuadres para mostrar asuntos educativos poco reflexionados en Occidente ${ }^{1}$.

\footnotetext{
Uno de los cineastas que en el nuevo milenio más ha contribuido a la reflexión sobre la naturaleza de la imagen cinematográfica es Abbas Kiarostami, su capacidad para jugar con lo que el cine mira y cómo se relaciona con la realidad, permiten que el espectador no se sienta guiado hacia una interpretación, más bien se sienta situado ante aquello que puede derivar de su propia mirada. En esta misma vía se ubica la grandeza de la joven cineasta Samira Makhmalbaf quien hace de la imagen un recurso para hacer visible a través de la invisibilidad y para la ubicación de situaciones límites.
} 


\section{El encuadre para otras miradas}

A propósito del inicio de un excepcional viaje de formación doctoral, un maestro, en el marco del Seminario "Pedagogía, Escuela y Cine, propuso un encuentro para lo que podría ser una especie de ejercicio de educar la mirada².

Desde el seminario, aparecía con especial fuerza la necesidad de mirar la propia mirada ${ }^{3}$, se reafirmaba la necesidad de pasar por riscos, abismos, destierros, expulsiones, exilios, emboscadas de pensamiento, para inquietarse de otros modos, a propósito del cine, por la educación y la investigación en educación.

Relecturas y redimensionamientos sobre las maneras naturalizadas de pensar las prácticas educativas eran absolutamente necesarias, se trataba de ampliar el campo de

2 Lo cual alude a la propuesta del pedagogo y amante del cine Alain Bergala contenida en el libro que hacia 2007 fue traducido al español, titulado por su autor como La hipótesis del cine. Pequeño tratado sobre la transmisión del cine dentro y fuera de las aulas. Este ha sido utilizado de inspiración en muchos grupos e intelectuales del mundo para pensar qué le pasa a la escuela cuando la escuela coge al cine y qué le pasa al cine cuando se proyecta en ese extraño lugar que es la escuela. Entre esos intelectuales que se han ocupado de la mencionada relación cine-educación están Ines Dussel y Daniela Gutiérrez, quienes con el apoyo de la Fundación Ford, hacia 2005, organizaron en Argentina el Seminario Internacional "Educar la mirada: políticas y pedagogías de la imagen", a través del cual se propició el debate sobre los medios y modos de producción de imágenes y su relación con la educación. El Seminario se recogió en un libro compilado por estas dos investigadoras y que titularon de igual forma que el Seminario. Educar la mirada, señalan estas compiladoras en la introducción al libro, es una apuesta "no en el sentido de 'educare' (educar-enseñar) sino de 'e-ducere': salir, estar fuera, partir. Sostener la atención, caminar hasta el agotamiento, no querer llegar a 'algo', es un modo de des-aprender, de liberar la propia mirada en el sentido de despojarla de cualquier prejuicio o destino prefijado" (Dussel, 2006, p. 19).

3 En esta misma vía vale la pena detenerse en el artículo de Ana Abramowski (2008) titulado "El lenguaje de las imágenes y la escuela: ¿es posible enseñar y aprender a mirar?", en el cual se detiene sobre la relación entre ver y saber. "¿Qué vemos cuando miramos? ¿Solo vemos lo que sabemos? ¿Es posible ver más allá de nuestro saber? ¿Lo que vemos interroga nuestros saberes? Es cierto que nuestros saberes configuran nuestras miradas —el ejemplo más claro es que, frente a una misma imagen no todos vemos lo mismo-. Pero también es posible que, ante una experiencia visual, nos encontremos 'viendo' más allá de lo que sabemos o de lo que esperábamos ver: una imagen puede cuestionar nuestros saberes y desestabilizarlos. Es por esto que la simple pregunta '¿qué ves?' puede inaugurar recorridos inesperados". En: http://tramas.flacso.org.ar/articulos/ el-lenguaje-de-las-imagenes-y-la-escuela-es-posible-ensenar-y-aprender-a-mirar. (Consultado en octubre de 2012) 
visión para la investigación, de pensar de otros modos la contingencia, la complejidad ${ }^{4}$.

El viaje no era de obediencia, no era de cuaderno, no era de palabra ajena, no era de falsa erudición por cúmulo de información, era de umbrales, de márgenes, de ruptura con formas habituales de pensamiento, de exhortación a otras formas de inquietarse, de incitación y provocación a ir construyendo el propio camino.

Se presentaba un recurso de aquellos que no deja indiferente, una estrategia desde la cual era posible crear un propio microrrelato a partir de otros relatos, el cine.

4 Ampliar el campo de visión implicaba detenerse, excavar, profundizar, detallar, agujerear en aquello que aparecía evidente, ya visto y seguro al ser expresado por otros. Implicaba como en la película de Antonioni, Blow Up, estar dispuesto y atento a que algo no visible se presentará en su campo de visión.

La película inspirada en el cuento "Las babas del Diablo" de Cortazar, muestra cómo una fotografía instantánea al ser revelada, enseña a un afamado y exitoso fotógrafo algo que él mismo no esperaba ver. Algo que se encontraba encuadrado por la cámara, en su campo de visión y que había pasado inadvertido, fue capturado: un crimen. Este suceso inesperado, contingente, casual, hace que para el protagonista de la historia, la captura inicial y guiada, pase a un segundo plano, ubicando su atención en lo incierto, descentrándolo de su punto de partida para derivar en algo no previsto. Lo inesperado, capturado en el encuadre y evidenciado por un campo de visión ampliado, condujo al afamado fotógrafo a modificar la relación con su profesión y con las lecturas habituales del mundo. En la película Antonioni muestra que la imagen fotografiada puede ser una creación en tanto el fotógrafo arma una realidad con un propósito específico o la recorta a su antojo. Sin embargo, aquello que vemos como si solo fuera una ficción, se confunde con la realidad, en la medida en la que la fotografía retrata un hecho/acción que sucede.
[...] En el fondo lo que busco es suministrar un campo de visión amplio, complejo, ancho y ajeno como lo expresara estéticamente Ciro Alegría. Planteo el seminario en términos de relaciones móviles, con articulaciones parciales, pero también susceptibles de lectura desde sus bordes, un investigador sabe situarse al margen y contemplar todos los detalles. Un adentro de cómo se investiga y un afuera de sus propias limitaciones. Como seminario doctoral interroga la aspiración formativa de un especialista, de un experto en favor de la formación de otro tipo de pensamiento. (Martínez, 2011, p. 1).

El cine como recurso para otro tipo de lecturas se constituía en una pro-vocación potente para buscar, excavar y revelar piezas, calcas y huellas de otros órdenes acerca de la educación y de las formas habituales de ser pensada. El cine enfrentaba a quiebres en investigación, a otras relaciones entre el ver y el saber, el cine mostraba que no basta con ver, mirar y con mostrar.

El cine insinuaba que no se trataba de lo que permanece para ser reproducido, se trataba del movimiento, del cambio, de las mutaciones que se han dado en la gramática 
y en la forma escolar, y que por tanto, cualquier investigación necesariamente debía ocuparse de ellas, mostrando a la par las condiciones de posibilidad desde las cuales se construyen los objetos de la investigación educativa.

El cine instó a detenerse en los cercos ideológicos desde los cuales se piensan los objetos de investigación en educación y arrojó a otro tipo de fragmentos desde los cuales es posible releer y redimensionar lo que resulta obvio. Dicha preparación era para la dislocación, para la sospecha, para el afuera ${ }^{5}$.

A esto apuntaba la invitación reiterada a ampliar el campo de visión en investigación educativa, a detenerse sobre lo que otros ya habían visto, a ampliar el zoom para detallar en vestigios, en los desechos, en lo visto pero ignorado por otros; era la invitación a aquello que arroja otras miradas, que saca de los supuestos causales y lineales para crear otros planos. A esto apuntaba la invitación a investigar de otros modos, a jugarse como en el cine, al movimiento, a jugarse con otras panorámicas, con otros zoom, con otros planos-secuencia, con rupturas con los encuadres ya dados y seguros para dar lugar a re-encuadres, a otras selecciones de la imagen.

Así como en el cine, según la situación en la que se coloque la cámara, distancia o ángulo de mira, la selección realizada, es decir el encuadre, puede variar sustancialmente la visión de la realidad, en la investigación, la búsqueda para configurar la masa documental, las profundizaciones en la búsqueda de fuentes, el zoom sobre los documentos y la configuración del archivo, determinarán/ modificarán tanto la cuestión y objeto a investigar como los propósitos de la misma con respecto a lo enunciado por otros. El encuadre y el campo de visión serían centrales para ubicarse de manera distinta ante lo investigado y ante lo proyectado por cada uno en las investigaciones doctorales.

5 A ello contribuyó la reflexión sobre la película mencionada antes Blow Up de Antonioni, en la cual este cineasta italiano muestra que gracias al enigma y al juego entre lo prohibido y lo permitido, algo nuevo cobra sentido pese a que se escapa eso enigmático que tiene pretensiones de verdad. Esa verdad no existe, máxime si no hay testigos, esa verdad se desvanece y devuelve la pregunta al sujeto que mira por que intenta reducir el enigma a una certeza. El texto visual dice de otro modo si la pretensión no es de transparencia, de resolución; dice si es posible que resista la tensión entre lo instituido y lo emergente; dice si se acerca al arte al dar lugar a lo nuevo y a lo incierto, y dice si con la lentitud, apacibilidad y silencio, se acerca con curiosidad y anhelo de descubrimiento a los trazos, que un día sugirieron que lo que se veía era cierto. 
El cine mira a la educación, y por su particular observancia, estimulaba a sospechar de la mirada que la educación ha hecho de sí misma. No era nada fácil, el seminario movilizaba, de-construía, interrogaba; su aporte era de la incitación, conmoción, desconcierto, de la no-seguridad. Desanudar la propia mirada de aquello desde lo cual hemos aprendido a mirar y liberar el ojo de aquello prefijado para explicarlo todo desde causas y purismos era la principal apuesta, por eso el seminario como punto de partida instigaba a mirar la propia mirada.

Lanzo este seminario
desde una actitud in-
vestigativa que pone en
discusión los temas de la
educación y de la peda-
gogía, en sus entramados
de relación con la cultu-
ra, con el arte, con la éti-
ca y con la estética que
le son inseparables al
trabajo intelectual. Ofer-
tó esta posibilidad por-
que reivindicó tanto la
creatividad como la cu-
riosidad, esa especie de
curiosidad que hay que
practicar con cierta obs-
tinación y que nos obliga
a alejarnos de nosotros
mismos. La investigación
logra ser una pasión solo
en aquellos momentos
en que roza con la vida,
lo que me hace ratificar,
cada vez con mayor con-
vicción, el papel priori-

tario de la educación de los sentidos en la labor investigativa. Ampliar el campo de visión para pensar los objetos de estudio doctoral agrega a los problemas velocidad, contingencia, angustia $y$ complejidad, condimentos sin los cuales, no valdría la pena pensar. (Martínez, 2011, p. 1).

El seminario contribuyó a que algunas de las preguntas de investigación que provenían de un tipo de encuadre, se deshicieran, se volvieran incompletas, irresueltas, pendientes y que empezaran a cruzarse e integrase con otro tipo de niveles, con otro tipo de relatos, narrativas, dis-continuidades, entre estas, una especialmente contundente: la narrativa metodológica e investigativa del Grupo de Historia de las Prácticas Pedagógicas ${ }^{6}$.

\footnotetext{
El Grupo Historia de las Prácticas Pedagógicas fue liderado hace poco más de tres décadas por una mujer que desde el campo de la filosofía y de las ciencias de la educación se propuso otras formas de investigación en educación, dando especial lugar a la historia de la práctica pedagógica en Colombia y a otras formas de pensar la historia de la educación. Este empeño de la profesora Olga Lucía Zuluaga fue materializado a través de un trabajo en equipo de docentes-investigadores de diferentes universidades como la de Antioquia, la Pedagógica Nacional, la del Valle, la Javeriana, la Nacional de Colombia y la del Cauca. Hoy el Grupo cuenta con 8 miembros fundadores (Alberto Martínez Boom, Alejandro Álvarez Gallego, Carlos Noguera, Javier Sáenz, Jesús Alberto Echeverry, Oscar Saldarriaga, Humberto Quiceno y Olga Lucía Zuluaga), y con un conjunto de profesores y estudiantes que se forman a través de las diversas actividades académicas entre las que se encuentran la oferta de formación avanzada en maestría y doctorado.
} 


\section{El encuentro cine-educación}

Lo que parecía una relación obvia por el hecho de tener como escenario o contexto la escuela y como protagonistas el profesor y el estudiante, se tornó una especie de alerta, no se trataba de un consumo cotidiano y ocioso del cine.

El encuentro cine-educación estaba determinado por una provocación a un pensamiento del afuera, a una mirada develativa del campo de visión a través, entre otra cosas, de construir y mostrar los casos que se hacen explícitos en el cine. ¿Cómo, a partir del cine, podíamos pensar los problemas de la pedagogía, la escuela, la enseñanza? ¿Constituye el cine una experiencia pedagógica? ¿Qué hace comunes y cercanos al cine y a la educación? ¿Cuáles son las mutuas inclusiones y exclusiones entre el discurso del cine y el de la educación? Eran algunas de las preguntas movilizadoras.

Algunas de las películas propuestas y analizadas dejaban entrever que el campo intelectual de la educación era necesario interrogarlo, interpelarlo, inquirirlo, pues asuntos como el saber de la escuela, el lugar político de la escuela, el lugar de la infancia, la forma maestro, el sujeto que aprende, la normalidad que normaliza la escuela, entre otros, estaban siendo mirados de otros modos por el cine, favoreciendo e incitando la sospecha de explicaciones naturalizadas sobre dichos asuntos ${ }^{7}$.

Este grupo de investigación es quizás uno de los más reconocidos en América Latina por proponerse otras formas de investigación en educación y por proponerse la consolidación de una comunidad de intelectuales que, desde distintos enfoques, comenzarían a pensar la pedagogía como saber específico. A través de las cinco líneas de investigación (formación de maestros; historia de conceptos y relaciones conceptuales; pedagogía y cultura; políticas educativas; y recuperación de la memoria educativa y pedagógica), el grupo con una caja de herramientas inicialmente inspirada en el pensamiento foucaultiano, se ocupa tanto de objetos, como de metodologías desde las cuales se cuestionan las formas convencionales de hacer investigación educativa en el país.

Tres puntales son claves para repensar de otras maneras la investigación: 1. la propuesta arqueológico-genealógica de Foucault para pensar, entre otras cosas, el concepto de historia del saber; 2. el archivo como posibilidad para otras formas de periodización en historia de la educación y la pedagogía, y 3. la relación saber-discursos-prácticas para pensar la historia como prácticas de saber, como formas de lo dicho y como análisis de la memoria del saber institucionalizado. En estos tres puntales, la transversalidad, los entramados, las emergencias, los saberes residuales, cumplen un papel fundamental. (Ver página web de Grupo: http://historiadelapracticapedagogica.com/)

7 Era un ejercicio para una práctica renovada, era una apertura para "educar la mirada". Se trataba de una compleja tarea para el pensar, como lo señala Nelly Richard (citado por Dussel, 2006) en la introducción al libro Educar la mirada: políticas y pedagogías de la imagen, "[...] la tarea es rasgar las superficies demasiado lisas con marcas de descalce, marcas que abran huecos (de distancia, profundidad, extrañeza) en la planicie de la comunicación ordinaria. Debemos educar la mirada para ver bajo la lisura los quiebres y dobleces del pensar insatisfecho".(p. 15). 
Implicaba lo que Diker y Frigeiro (2005) señalan como una dislocación en las formas de mirar la escuela y de pensar las posibilidades políticas de la misma,

[esto] exige invertir los sentidos históricamente construidos acerca del cambio en la escuela. Ello implica, en primer lugar, pasar de una mirada normativa y mitificadora del pasado a una mirada con vocación histórica que busque en el pasado claves de interpretación de los cambios que tienen lugar en la cultura contemporánea y no imágenes apocalípticas de deterioro; en segundo lugar, implica abandonar la pretensión prescriptiva propia de la pedagogía $y$, con ella, la pretensión de generar nuevas categorías para anticipar lo posible (o, más bien, lo probable) y nuevas prácticas para volverlo posible real. En tercer lugar, implica asumir no solo que el cambio en las escuelas es posible, sino que las escuelas ya han cambiado. También, que los signos de cambio en las escuelas no vienen sólo de la mano de los alum- nos ni, por supuesto, solo de la mano de aquellos alumnos que la escuela se propone incluir cada vez en mayor número ( $p$. 136).

El cine, sin duda alguna, problematizaba y resituaba, se trataba ahora de pasar de un consumo habitual del cine en educación a uno menos convencional: la educación al cine, lo cual obligaba a un afuera, a una distancia, a la exterioridad necesaria para pensar las representaciones sobre el mundo educativo de otras maneras. La educación al cine implicaba atravesar lo fijo, cerrado, estático y universal de las formas escolares para otro tipo de lectura, con otro zoom, con otra mirada, con el ojo que pareciera inventa el cine para ver y demostrar de otras maneras.

El desafío de pensamiento se encontraba en el acontecimiento, en los agenciamientos, en lo inesperado, en la lejanía y en las maneras posibles, emergentes e inciertas de pensar la forma educación desde el cine. Se trataba también de mirar ...la escuela y el cine
como parte de los inten-
tos de modernización de
la cultura y la sociedad
en los comienzos del si-
glo XX. Porque, aunque
la escuela sea más vieja
que el cine y hoy cueste
verle algún parentesco 
con él, si se la mira históricamente, no hay duda de que hay que ubicarla dentro de la serie de las tecnologías que buscaron producir nuevos sujetos en el cambio de siglo anterior. (Serra, 2011, p. 12).

Se presentaba entonces a condición de relación, y para pensar de otros modos, la emergencia histórica del cine y la consolidación de la forma escolar ${ }^{8}$.

La educación al cine trascendía las impresiones iniciales sobre determinados aspectos de las películas, situaba ante la palabra por venir y ante el carácter inconcluso de la narrativa. Poco a poco se fue dirigiendo la mirada tanto a los cambios que desgastan los cimientos de la educación, como a las problemáticas sociales que desrealizan las promesas sobre las cuales se sostiene la esperanza en la educación misma. Algunas de las películas y la sospecha sobre las preguntas de investigación de los proyectos doctorales, así lo favorecieron.

\section{A propósito de la película ¿Dónde está la casa de mi amigo?}

Esta imponente película dirigida por el cineasta iraní Abbas Kiarostami, y cuyo título está inspirado en el poema "La dirección" de Sohrab Sepehri, es, sin duda, una posibilidad para cavilar desde otros lugares la dilución del maestro ${ }^{9}$, el lugar del cuaderno como repositorio de saber que es examinado y la relación pedagogía-escuela a través del cine.

8 Esta consolidación de la forma escolar estaba relacionada con una práctica que posteriormente retoma el cine y que prefigura la escuela: la idea frontal de la atención que inaugura la escuela. Al respecto la investigadora Inés Dussel (2009) en un artículo publicado en la revista colombiana Nómadas No. 30 refiere: "...Las escuelas, y los docentes en particular, han sido claves en la transformación de los regímenes escópicos modernos (cuyas transformaciones actuales son motivo de muchos debates, como lo muestra el trabajo de José Luis Brea (2006), entre otros). Jonathan Crary ha apuntado lúcidamente los cambios epistemológicos y políticos que tuvieron lugar entre los siglos XVIII y XIX, que reorganizaron las posiciones del observador y de lo observado, las relaciones entre saber y poder, los aparatos y los discursos institucionales implicados (Crary, 1995). En un trabajo posterior (Crary, 2008), estudió la cuestión de la atención como eje de una preocupación pedagógica, política y epistemológica, que estuvo en la base del afianzamiento del espectáculo moderno. Captar la atención del espectador, y también del alumno, se volvió un elemento central de la acción educativa, de la escuela y de otros medios como los salones de pintura, las exposiciones universales y el incipiente cine" (p. 184). Esta organización de la atención como organización frontal la inaugura la escuela pero la resitúa el cine, el espectáculo está al frente y algo nos deja hipnotizados mirando a la pantalla. El atender para aprender de la escuela hace la antesala a ésta forma de mirar. 
Mediante trayectos y trayectorias, el juego de la imaginación y la apreciación y el desplazamiento interiorexterior, Abbas Kiarostami conduce a pensar la escuela como un acontecimiento histórico que es necesario interrogar hoy a partir de la triada disciplinamiento-tiempo-espacio. Para ello se vale de múltiples recursos que van desde el detalle de odiseas infantiles en las que se resitúa la figura del niño, hasta la tradición y la época contenida en las cambiantes forjas de mobiliario.

¿Dónde está la casa de mi amigo?, filmada a finales de la década de 1980, es una particular construcción $^{10}$, en la que una historia mínima es narrada de tal forma, que se muestran con un carácter intimista, los detalles de una tragedia cotidiana de un niño que se relaciona de manera distinta la normatividad y disciplina de la escuela.

El nombre de la película es una pregunta, formato inusual en titulación de películas en el cine. La pre-

10 Su particularidad obedece igualmente a lo expresado por Villalobos (2006) sobre el cine de Kiarostama "... La narración y el montaje de imágenes y escenas son tan naturales que hacen de la trama un delicado transcurrir de lo insignificante [...] Con sus películas se hace posible retomar una pregunta crucial para la reflexión estética y visual contemporánea, a saber, ¿cómo se manifiesta en ellas la relación entre experiencia, imagen y narración? O, para decirlo de otra manera, se hace posible preguntar no por una particular relación entre cine y política, ni menos por la condición partidaria de su propuesta fílmica, sino, más radicalmente, por el cine en cuanto política. De esta forma, retomo también la interrogante que he dejado pendiente en la primera parte, a saber, ¿cómo pensar la relación entre imagen y poder, en el cine, que es, básicamente, una invención moderna?" (p. 9). gunta no alude a una ubicación espacial específica, no alude a una locación que se ha de señalar, es una metáfora sobre el trayecto, el camino, la búsqueda, el movimiento; es una metáfora sobre el viaje.

De ahí su interés por trabajar en espacios y sobre los espacios, caminos en zigzag, territorios, fronteras, linderos, acompañan el juego de composiciones de Abbas Kiarostami quién hace visibles, entre otras cosas, los caminos de la creación, de los breves viajes de la vida, muchos de ellos por fuera de la escuela, del sistema disciplinario, muchos de ellos posibles en la transgresión y en el riesgo para otro tipo de identidad. En los caminos, en los recorridos, en aquello que se recorre como apuesta propia más allá de las normas que insinúan su prohibición, hay micromundos que se exploran, se descubren, se conocen. Los acontecimientos del camino, las soledades que acompañan y las incertidumbres sobre lo que será y aparecerá, resultan contundentes para mostrar que frente al poder autoritario de las tradiciones encarnadas en la escuela y por fuera de la misma, y ante la voluntad personal de un niño, hay un punto de no retorno a nivel personal.

El lugar del silencio, el paisaje que se despliega silenciosamente en la distancia y el viaje 
repetitivo de ida y vuelta, dan fuerza a la tensión entre el tiempo real y el tiempo ficcionado: el tiempo narrado, lo que permite leer de otra manera la escuela en tiempos de velocidad.

Kiarostami muestra como un conjunto de acontecimientos que se suceden en un tiempo breve, en el inicio de un día escolar, narrados en los primeros cinco minutos de la película, dinamizan la singularidad, las relaciones, las búsquedas, los dilemas del protagonista, esos cinco minutos marcan lo que será un acontecer de vida, incluso en contravía de lo hegemónico social. . Kiarostami se detiene con detalle en los tiempos de lo escolar y se ocupa con sigilo y profundidad de las formas del tiempo existencial que le resultan cada vez más ajenos y riesgosos a la escuela tradicional. El tiempo de la infancia en la escuela, las promesas del tiempo que vendrá sobre las cuales afinca la escuela sus promesas, el tiempo quebrantado en una sociedad aldeana cambiante, el tiempo que organiza, regula y copta la escuela para ordenar y decretar, el tiempo testificado en el cumplimiento de las obligatorias tareas escolares visible en el cuaderno, entre otros, hacen que este cineasta iraní lleve al espectador a interrogarse la naturaleza del tiempo en la forma escolar en contracara con un tiempo existencial como infinitud inasible e inefable. Kiarostama irrumpe en las formas de la escuelar para quebrantar los supuestos del tiempo de la cultura como si fuera un universal. La película es en sí misma un esfuerzo por esculpir el tiempo a través de los personajes, jugándosela en el tiempo del cine con otras lecturas posibles desde el fluir del tiempo. ¿Cuál es el tiempo que detiene la escuela? ¿Sobre qué tiempo esculpe la escuela sus promesas? ¿El discurso del deber ser de la escuela imprime el sello en las conductas de los sujetos para qué tiempos? ¿Qué tiempo es aquél que se pide detener en el cuaderno? ¿Sobre qué se sustentan los tiempos límites para el ejercicio de la disciplina en la escuela? ¿Qué tiempo es aquél que prefija la escuela con las tareas, las correcciones y las repeticiones? ¿Qué perdurabilidad promete lo que se evalúa en la escuela bajo la ficción de lo que servirá o se utilizará?

Haciendo uso de fotografía y de composiciones especialmente configuradas en lo elemental, este cineasta muestra la vida que acontece por fuera de la escuela y la tecnología de la disciplina que a su vez opera dentro de ella. Los cinco primeros minutos de una vivencia escolar y la forma como se narra, son 
una ventana para leer la sociedad, a sus actores sociales, instituciones, sistemas normativos, modos de producción; para leer con otros ojos, los del protagonista, la vida que acontece por fuera de la escuela que pareciera incierta.

Lo anterior se complementa con lo que muestra Kiarostami de la relación adentro-fuera en una comunidad aldeana cuya vida gira en torno a las actividades familiares y de producción colectiva. En dichas actividades la escuela llamada: Instituto para el Desarrollo Intelectual de los Niños desempeña un papel especial, no solo porque encarna la fuerza del cambio (paradójicamente desde la perpetuación de valores), también porque es garante de lo que se requiere en un mundo laboral al que se ha de llegar, listo en la vida adulta, y que se soporta en distribuciones sociales inamovibles y en la obediencia.

La relación familia-escuela enrostrada de manera contundente en la película, le permite al espectador evidenciar que la escuela ignora la vida de los niños en la familia y que la familia ignora la vida de los niños en la escuela. Los límites entre las instituciones están marcados; cada una tiene un adentro, unas rutinas, un mundo de prescripciones; cada una marcha sobre tiempos, ambientes, autoridades. Más allá de ello, la película muestra que hay un conjunto de implícitos y acuerdos entre familia y escuela en torno a la disciplina y el castigo, amparados en el discurso de los deberes y de la obediencia. Familia y escuela amparan el discurso del deber ser y de la disciplina en las promesas de un mañana, ellas inscriben en relaciones de autoridad y obediencia, la escuela desde un discurso pedagógico disciplinado, de "buena conducta" y la familia en una autoridad generacional de "buen niño". La ocurrencia de faltas y la amenaza de castigos así lo evidencian.

\section{Sobre la figura de maestro en la casa de mi amigo}

La película pone en tensión la figura del maestro. Por un lado, da cuenta de representación maestroprofesor, el cual desde el orden que promueve garantiza que hay escuela, promueve la reproducción, el deber verifica, sanciona, castiga, disciplina, compara el aprendizaje de un antes y un después, a partir lo contenido en el cuaderno. Es la figura del maestro-profesor ${ }^{11}$ cuyo ejercicio de educación reside en las prescripciones, en la disciplina y las tradiciones. El profesor que activa y

\footnotetext{
11 Al respecto Martínez Boom (2010) señala: " se habla tanto de los maestros que no parece quedarles ni oscuridad ni respiro. Cuando se habla tanto del maestro ya no se sabe qué es lo que se dice de él, o algunos creen que con definir su perfil están resolviendo sus problemas [...] Esto me hace pensar que el lugar del profesor en la escuela fue definido en su origen por condiciones de posibilidad que ya no son las de ahora y que tal proliferación de discursos se debe a los vanos intentos de definir qué es hoy un maestro. Si la escuela ha cambiado, si la infancia ha cambiado, si el saber ha cambiado, el maestro no puede ser ajeno a estos cambios".
} 
pone en juego la tecnología de la disciplina. Que favorece la secuencia para interiorizar la norma: primero los deberes y después el juego.

Es aquél profesor que sitúa Kiarostama en los cinco primeros minutos de la película y que, a partir de un evento aparentemente determinado por el azar y forjado en la disciplina, determina considerablemente la vida del niño.

Por otro lado, muestra la figura del maestro-mentor ${ }^{12}$ encarnada en el artesano, en un hombre anciano-sabio que interroga sobre las pistas que debe tener el niño para saber a dónde ir; el artesano como el maestro que acompaña en el camino, en el afuera, que muestra dónde está la casa del amigo. Es la figura de quien es capaz de la hospitalidad y de la amistad de la cual habla Derrida ${ }^{13}$, es el maestro que es capaz de ponerse en el lugar del otro, que impulsa, que da fuerza para seguir en el camino ${ }^{14}$.

El maestro-sabio se compromete a acompañarlo. Por el camino le transmite un saber: le habla de las puertas viejas y de las nuevas, de la vida en el pueblo y de la ciudad. En el camino le muestra que las cosas están cambiando, una nueva época se avizora, lo que se refleja en el cambio de materiales de las puertas y ventanas, advierte que aun en la aldea la in-

12 Para una historia del maestro en Colombia vale la pena revisar, entre otros, el artículo del investigador e integrante del Grupo de Historia de las Practicas, el profesor Alejandro Alvarez Gallego, titulado El maestro: historia de un oficio (ver versión digital en: www.pedagogica.edu.co/storage/nn/articulos/nodynud01_11hoje.pdf). El libro de la profesora y fundadora del Grupo en mención, Olga Lucia Zuluaga titulado Pedagogía e Historia; y el artículo del investigador de la Universidad de Antioquia e integrante del GHPP, Orlando Castro y otros, De la profesión a la función docent (versión digital en: www.uptc.edu.co/facultades/f_educacion/.../psicopedagogia5. pdf

13 La hospitalidad es un texto escrito por el filósofo Jaques Derrida, hacia finales de la década de 1990, posteriormente fue retomado por Bourdieu y se alude constantemente a ella para proponer la alteridad en el mundo escolar, tal es el caso de intelectuales como el argentino Carlos Skliar y el español Jorge Larrosa. Para Derrida, la hospitalidad está relacionada con el encuentro con el extranjero, el vagabundo, el extraño. La hospitalidad está relacionada con la solidaridad, con el alojamiento, con la similitud y la diferencia. La hospitalidad es aquello que se abre hacia el rostro, lo que lo acoge.

14 El camino es una de las tantas metáforas que utiliza Abbas Kiarostami para representar la vida, recreada y en libertad. Los trayectos, los recorridos, itinerarios son opciones para contrastar los caminos de los otros, con las vidas de los otros. El sentido de la vida implica recorrido, trayecto, transgresión, exploración de lo que hay más allá. Frecuente en sus fotografías y con un juego de encuadres constantes utiliza los caminos para dar profundidad, para representar la soledad, lo incierto y para representar lo que está por conquistar aun en medio de la oscuridad y del miedo. La transgresión y la libertad pareciera son dos herramientas para los viajes de vida. 
dustrialización asoma. Le muestra también que frente al cambio hay también otro tipo de saber, otro tipo de mirada, la del manantial, otro tipo de aprovisamiento existencial, por ello, en el camino le dice: "Ten, toma esta flor y métela en el cuaderno. ¡No la pierdas! ¡Debes guardarla!". Es el objeto, que aparentemente insignificante, encarna otro tipo de esperanza, es la metáfora de la posibilidad de tener otro lugar en la escuela disciplinaria.

Kiarostama cuestiona al profesor de lo común y lo muestra también en el cambio, en la apertura. Al final de la película, el profesor de escuela que abre la ventana, ya no es ese profesor cuya autoridad está dada en la instrucción y en la obediencia.

Esto me hace pensar que el lugar del profesor en la escuela fue definido en su origen por condiciones de posibilidad que ya no son las de ahora y que tal proliferación de discursos se debe a los vanos intentos de definir qué es hoy un maestro. Si la escuela ha cambiado, si la infancia ha cambiado, si el saber ha cambiado, el maestro no puede ser ajeno a estos cambios. (Martínez, 2010, p. 4).
Algo se avizora en el horizonte, un tiempo de tránsito cobija hoy la educación ${ }^{15}$.

\section{Otros aspectos a pensar sobre la película}

- La niñez de la "buena educación" y la niñez de la escuela en expansión.

- El tiempo de la infancia, la infancia del cine, el tiempo interior y exterior de la infancia y la contribución del cine a la mundialización de la infancia ${ }^{16}$.

15 Silvia Duschatzky en el texto "Perplejidades incesantes, subjetividades de intemperie", a propósito del documental Entre líneas, se pregunta "... ¿Cómo pensar la existencia de la escuela en nuestros días, o mejor: cómo pensar-nos en el devenir de un tiempo desgarrado?" Al final del texto refiere "...hoy todas las formas de vida experientan el vacío de estar arrojados a un mundo revestido de contingencia. La "perturbación ominosa de estar expuestos a la intermperie, al tiempo que nos dispersa, nos coloca frente a la necesidad de poner a prueba nuestras capacidades constitutivas de composición social" En. Dussel. I. Educar la mirada.(2006, p. 207).

16 Al respecto señala Larrosa, J. (2007): "Tal vez podamos ver ahí una imagen otra de la infancia. No las imágenes moralistas y moralizadoras de la infancia que producen las ideologías pedagógicas, esas que siempre están queriendo conocer, comprender y ayudar a los niños, esas que nos invitan constantemente a 'ponernos en su lugar'. Tampoco las imágenes policiacas y controladoras que producen los dispositivos pedagógicos, esos que someten a los niños a una permanente vigilancia y, como Foucault nos enseñó, a una permanente normalización. Ni siquiera las imágenes arrogantes que producen las prácticas pedagógicas, esas que pretende enseñar a los niños lo que estos no saben (no solo 'saberes' en sentido estricto, sino también normas, actitudes, valores, formas de relación y de convivencia). 
- El rol del silencio: hay un silencio que silencia, el maestro, y un silencio del que habla el niño.

- La fuerza de la otredad frente al peso de las circunstancias, pues hay algo que sobrepasa el discurso policíaco de la escuela y el discurso de los deberes de la familia: la inquietud del otro.

- La importancia y la fuerza del desobedecer. La película se ocupa de la tensión obediencia-desobediencia. Hay música cuando el niño desobedece, cuando emprende camino. ¿Qué tipos de obediencia promueve la escuela hoy y para qué tipo de sociedad?

- Los discursos sobre el deber ser y el castigo en la escuela y la relación sujeto-autoridad.

- El lugar de la memoria en la escuela: ¿qué tipo de memoria requiere la escuela de la reproducción? ¿Qué memoria promueve la escuela hoy desde las formas de aprendizaje contemporáneas?

- El lugar del azar, de la incertidumbre, de la flor, del arte, de lo bello, la esperanza sobre lo que se reconfigura en educación.

- El cuaderno escolar, los discursos escolares del cuaderno limpio, el registro en el cuaderno y la visibilidad del saber.

- La historia del cuaderno escolar, los tránsitos de un cuaderno único a un cuaderno por asignatura, emergencias del cuaderno de borrador en la escuela y el lugar del cuaderno en el paso de

\footnotetext{
"Todas esas imágenes disminuyen a los niños con el pretexto de que los aman, o los protegen, o los educan. Mirar a los niños no es fácil. Y no solo por la fuerza abrumadora de esas imágenes pedagógicas a las que me refería antes. Tenemos también el uso y el abuso publicitario de la infancia, de cierto tipo de imágenes de la infancia, y no me refiero solo a aquellas que han sido objeto de debate por sus reales o pretendidas connotaciones sexuales. Por otra parte, las imágenes de la información oscilan entre la utilización masiva de ciertos estereotipos infantiles para apelar con ellos a una sensibilidad embotada, y el hábito, crecientemente asumido, de usar caretas o difuminados para ocultar los rostros de los niños y, según se dice, defender su derecho a la privacidad. Además, las cámaras de video-vigilancia son crecientemente utilizadas en los lugares frecuentados por niños y especialmente en las escuelas.

También el cine utiliza constantemente imágenes de infancia con propósitos descarados de identificación o de proyección emocional. Las imágenes de la infancia no representan a los niños, sino a nosotros mismos. Quizá no sea exagerado decir que las imágenes masivas de la infancia que producimos y consumimos nos impiden mirar a los niños, nos hacen ciegos para los niños. Quizá deberíamos aprender a mirar de nuevo y, como los habitantes de Hondareda, inventar ejercicios de mirar".
} 
una escuela centrada en la oralidad a una escuela centrada en la escritura.

- Encuentros entre el cuaderno y la pizarra escolar: atisbos de una tecnología escolar. (tiempo, actividad y contenido disciplinar).

- La dilución del maestro y los discursos escolares sobre el para qué saber.

\section{Sobre la figura del tablero en La Pizarra}

Esta majestuosa película iraní tejida en una especie de red visual y cuyo guión es escrito por Mohsen Makhmalbaf, y la cine asta Samira Makhmalbaf, muestra, a través de diversas metáforas, entre ellas la pizarra, las contradicciones y vicisitudes de un grupo de maestros que en medio de la guerra se enfrentan a la búsqueda de estudiantes para garantizar la supervivencia y para favorecer un lugar social radicalmente interrogado en medio del conflicto armado.

Centrada en el periplo de un grupo de profesores nómadas, cuya elección de su oficio es constantemente puesta en tensión por los dilemas personales y las posibilidades de reconocimiento social en medio de la guerra, este film cargado de símbolos como los abismos, los vientos, el tablero con sus diversos usos, permite pensar de otro modo los momentos y sucesos aso- ciados a la desestructuración de la pedagogía en periodos de quebrantamiento social y de fractura de los sistemas educativos a causa de la guerra.

Con una pizarra al hombro, este grupo de profesores que transita por las montañas kurdas, en la frontera entre Irán e Iraq, lucha por algo más que la sobrevivencia, lucha -utilizando la persuasiónpara que un grupo de jovenzuelos y de hombres mayores se convenzan de la importancia del aprender.

Pero, ¿para qué aprender en medio de la guerra? ¿Para qué aprender a partir de razones ajenas? ¿Para qué aprender si en el trasfondo de la guerra y la violencia la palabra, la herencia y el lazo social son invalidados e incluso aniquilados? ¿Para qué aprender si la acumulación de riqueza y la distribución del poder impiden las oportunidades para todos? ${ }^{17}$

La directora del film se ocupa con especial detalle de las condiciones de posibilidad del oficio del

17 Esta pregunta acerca del para qué en medio de la guerra y después de la guerra que lo recrea muy bien esta joven cineasta iraní, ha estado igualmente presente en el cine. Después de la Segunda Guerra Mundial hay una relectura del para qué del cine. ¿Qué hacer con el cine después de la guerra? ¿Qué puede hacer el cine en tiempos de posguerra? ¿Qué miradas puede hacer el cine de la guerra para efectos de la memoria colectiva? ¿Qué nuevas relaciones con la realidad se le piden al cine después de la guerra? ¿Qué permite el cine mirar, decir, y recrear a propósito de la guerra y de las huellas de la violencia en tiempos de posguerra? Incluso las teorías del cine cambian sustancialmente después de este conflicto. 
maestro en medio de un contexto de guerra, donde aquello sobre lo cual se soporta el poder y legitimidad de su rol, es inexistente.

\section{La figura del maestro y el para qué de La Pizarra}

Los maestros cargados de la esperanza que ofrece la pizarra (gracias a sus usos) esgrimen argumentos vacíos para crear ilusión de mañana y para prometer otras miradas del mundo en medio de los vestigios de una humanidad interrogada tanto por la guerra, como por el monopolio de la riqueza y las incambiables clasificaciones sociales.

A los veinte minutos de iniciar la película, Reeboir, uno de los profesores protagonista de la historia intenta convencer al grupo de muchachos contrabandistas de la importancia de saber leer, escribir, sumar: "Puedes aprender a sumar... restar, hacer tus propias cuentas sin ser engañado... Tan bueno es todo eso. Podrías estudiar o encontrar un trabajo" insiste Reeboir. El niño contesta: "¿Hacer las cuentas...? Eso es genial para un jefe... nosotros somos mulas... siempre en movimiento... ¿Cómo quieres que leamos? Para leer hay que estar sentado".

La quietud y el estatismo de la escuela es interrogada en un mundo donde la eficacia del saber tiene otras formas de manifestación. ¿Cuál es la utilidad del saber? ¿Qué es lo que propone e imparte el maestro en materia de aprendizaje cuando está debilitada la comunicación con la realidad? El maestro insiste en hacerse visible en medio circunstancias que lo hacen invisible. ¿Frente a problemas prácticos de la vida, qué es lo que el maestro insiste en enseñar?

La Pizarra muestra al maestro desde diversos rostros y ángulos, pasando del maestro que no sabe a dónde va, al maestro que siempre es portador de un saber atribuido; su rol descansa en la fe que convencer a otros de que quieran aprender, le permitirá aparecer desde lo que tiene por enseñar.

Su rol descansa en la ficción de un lugar social: el maestro como servidor de la comunidad, como ser que conduce, que ofrece esperanza, y es una ficción porque se va diluyendo en medio de la guerra, la pobreza y en medio de los estancos de la sociedad.

Con la metáfora del maestro nómada, esta joven cineasta interroga el lugar social del maestro y muestra que las luchas y vicisitudes a las que socialmente se enfrenta, han estado presentes en otras culturas y en otros momentos históricos, instigando a 
que el espectador se permita pensar la ruptura, la fractura, los estatismos y la quietud con respecto al ser del maestro hoy.

En este tejido visual en el que de manera permanente el sentido del sufrimiento y la dificultad se captura y se intensifica, el maestro trastabilla, los abismos propios de un paisaje agreste lo empujan al movimiento, a la cautela, pues hay constantemente en medio de la guerra augurios de muerte que lo incitan a la protección de sí y de otros con aquello que encarna la pizarra, y lo convocan a seguir en un camino de búsqueda con otros e incluso para otros, para llegar a lugares en los que tiene que decidir si pasa o no la frontera.

Este maestro, sobre el cual fija la mirada Samira Makhmalbaf en gran parte de la película, es el maestro que enseña con la repetición monosilábica, es el maestro basado en la instrucción cuya visibilidad está dada sobre un estatuto hoy débil, frágil y que le recuerda que es ajeno. Es un maestro cuya vos es frágil, ajena, falseable por los problemas prácticos de la vida. ¿Por qué creer en el maestro y en sus verdades enunciadas? ¿Por qué creer en sus promesas de mañana y en la utilidad del saber de la escuela en inamo- vibles modelos de clasificación social?

En algunos episodios de la película se muestra con majestuosidad que las promesas de saber en diversos contextos requieren de un asidero de realidad y requieren mayor conexión con problemas sociales con gran sentido práctico: defensa de la vida, satisfacción de necesidades básicas, enajenamiento de la libertad y escases de oportunidades. Esta joven cineasta lleva al espectador a interesarse por el saber de lo que es el saber, desde los aspectos relacionados con su desarrollo y formas de distribución en la sociedad donde este es posible.

\section{La expulsión del maestro}

¿Qué es el maestro sin la pizarra? ¿Sobre qué se afincan en determinados momentos históricos las seguridades de su existencia? ¿Por qué la necesidad de autoafirmación en momentos en los que no hay maestro si no hay otros que lo reconocen?

La Pizarra permite poner en primer plano la crisis de los saberes, los límites del mismo y las certidumbres sobre las cuales se basa la supuesta actualidad del acto escolar. 
¿Cuáles son entonces los otros usos de la educación? ¿Dónde se juegan las promesas de la educación? ¿Quién necesita un maestro? ¿De dónde provienen las promesas de saber? ¿Qué es el maestro en esa sociedad? ¿Qué son los niños? ¿Cuál es la corporalidad de ese maestro? ¿Cuáles son las posibilidades para un conocimiento abandonado, obligado a probar y venderse a sí mismo en un mundo donde no hay sitio para él? ¿Qué quiere decir socialmente que repetir rápido es aprender rápido? ¿Por qué el maestro se pone cero? De aquí la importancia de la pizarra como palimpsesto, la pizarra demarca qué se puede enseñar.

A manera de cierre, los iraníes Samira Makhmalbaf y Abbas Kiarostami, a través de estas dos películas convocan al espectador a pensar de otros modos las fronteras de la escuela y las múltiples figuras del maestro; estos dos cineastas interrogan la escuela como escenario societal y cuestionan la relación del maestro con la sociedad.

Por su majestuosidad en la forma de mostrar el afuera de la escuela, llevan a la reflexión sobre los tránsitos en la figura del maestro y sobre los cambios en las condiciones de posibilidad para que incluso la escuela un día se hiciera necesaria.

El cine interrogaría la escuela, la interpelaría en sus formas de verse a sí misma y dislocaría las formas habituales de pensar asuntos educativos que incluso pueden ser vistos y predefinidos de forma ingenua en educación.

Estas dos películas, en el marco del seminario, dislocaron los supuestos investigativos que sirvieron de punto de partida para la investigación doctoral, era necesario hacer aparecer otra mirada, era necesaria otra forma de interrogar y era indispensable ponerse en riesgo para otro tipo de andar investigativo. El destino prefijado de la investigación había entrado en movimiento, se trataba ahora de una apertura al mundo. El encuadre de partida tendría que ser revisado, quedaba una especie de esperanza: el reencuadre, lo que implicaba una actitud límite que transforma y una apertura a otro espacio de existencia. 


\section{Referencias}

Abramowski A. (2010) Maneras de querer. Los afectos docentes en las relaciones pedagógicas. Buenos Aires: Paidos.

Abramowski, A. (2008) "El lenguaje de las imágenes y la escuela: ¿es posible enseñar y aprender a mirar?" En: http://tramas.flacso. org.ar/articulos/el-lenguaje-delas-imagenes-y-la-escuela-esposible-ensenar-y-aprender-amirar. (Consultado en octubre de 2012)

Alvarez, A. (1991) El Maestro: Historia de un oficio. Revista Colombiana de Educación No. 22-23, 140-158. Versión digital en: www.pedagogica. edu.co/storage/nn/articulos/ nodynud01_11hoje.pdf (Consultada en septiembre de 2012)

Amar, V.M. (2009) El cine y otras miradas: contribuciones a la educación y a la cultura. Salamanca: Comunicación Social Ediciones.

Badiou, A. (2005). Imágenes y palabras. Escritos sobre cine y teatro. Buenos Aires: Manantial.

Bergala, A. (2007). La hipótesis del cine. Pequeño tratado sobre la transmisión del cine dentro y fuera de las aulas. Barcelona: Laertes.

Bordieu, P. (Director). (1999). La miseria del mundo. Madrid: Fondo de Cultura Económica
Brea, J.L. (2007). Cambio de régimen escópico: del inconsciente óptico a la imagen. Revista de Estudios Visuales, 2(4), 145-163. Castro, O. et al. (2008). De la profesión a la función docente: Una mirada a la formación de los maestros desde los estatutos 2277 de 1979 y 1278 de 2002. Revista Cuadernos de Psicopedagogía. No. 5, 45-60. Recuperado de www.uptc.edu. co/facultades/f_educacion/.../ psicopedagogia5.pdf

De la Torre, S. et al. (2005). El cine, un entorno educativo. Madrid: Narcea Editores.

Derrida, J y Dufourmantele, A. (2000). La hospitalidad. Buenos Aires, Argentina: De La Flor.

Diker, G y Frigerio, G. (2005) Educar: ese acto político. Buenos Aires, Argentina: Del estante.

Duschazsky, S. y Sztulwark, D. (2011) Imágenes de lo no escolar. En la escuela y más allá. Argentina: Paidós

Duschazsky, S. (2007) Maestros errantes. Experimentaciones sociales en la intemperie. Argentina: Paidós

Dussel. I. (2009) Escuela y cultura de la imagen. Los nuevos desafíos. Revista Nomada, No. 30, 180-193.

Dussel, I. y Gutiérrez D. (2006) Educar la mirada: políticas y pedagogía de la imagen. Buenos Aires, Argentina: Manantial. 
Giusti, C. y Barbagelata, N. (2004) Psicoanalisis y cine: un dispositivo en extensión. Buenos Aires, Argentina: UNLediciones.

Larrosa, J. (2007). Las imágenes de la vida y la vida en imágenes. Revista Educación y Realidad, 2(32), 7-22. Recuperado de: seer. ufrgs.br/educacaoerealidade/article/download/6647/3964

Larrosa, J. et al. (1997). Imágenes del Otro. Barcelona: Editorial Virus.

Lattanzi, J.P. (agosto 2010) Una mirada a la escuela. Cine y educación en tres momentos históricos. Revista Reflexión académica en diseño y educación, 14, 107-109. Recuperado de: http://fido. palermo.edu/servicios_dyc/publicacionesdc/vista/detalle_publicacion.php?id_libro=380

Martínez, A. (2004). De la escuela expansiva a la escuela competitiva: Dos modos de modernización en América Latina. Bogotá: Editorial Anthropos-Convenio Andrés Bello.

Martínez, A. (2010). La dilución del maestro. Recuperado en agosto de 2012 de: http://palabramaestra.premiocompartiralmaestro. org/notitotal.php?idn=77\&idt=6

Martínez, A. (2011). Syllabus del Seminario Pedagogía, Escuela y Cine. Recuperado en septiembre de 2012 de http://es.scribd. com/doc/65021127/Alberto-Martinez-Boom y http://www.albertomartinezboom.com/home/

Martínez, A. y Álvarez, A. (1990). La formación del maestro: La historia de una paradoja. Revista Educación y Cultura, N. 20. Bogotá: Fecode.

Molina, J.G. (2012). Pensar, mirar, exponerse. Valencia: Nau Llibres.

Monsiváis, C. (2006). Se sufre porque se aprende. De las variedades del melodrama en Latinoamérica. En: I. Dussel y D. Gutiérrez (eds.). Educar la mirada: Políticas y pedagogías de la imagen. Buenos Aires: Manantial.

Serra, M.S. (2011). Cine, escuela y discurso pedagógico. Articulaciones, inclusiones y objeciones en el siglo XX en Argentina. Buenos Aires: Teseo.

Skliar, C. (2001), ¿Y si el otro no estuviera ahí? Notas para una pedagogía (improbable) de la diferencia. Buenos Aires: Miño y Dávila.

Villain, D. (1997). El encuadre cinematográfico. Barcelona: Paidós Ibérica.

Villalobos, S. (2006). Abbas Kiarostami: la política como estética minimalista. Revista Objeto Visual, 12, 2-18. Recuperado de: www. biopolitica.cl/docs/Villalobos_kiarostami.pdf

Zuluaga, O.L (1999) Pedagogía e Historia. La historicidad de la pedagogía, la enseñanza un objeto de saber. Barcelona. Anthropos. 